A. Potapova ${ }^{1}$, O. Egorova ${ }^{1}$, O. Alekseeva ${ }^{1}$, A. Volkov ${ }^{1}$, S. Radenska-Lopovok ${ }^{2}$. ${ }^{1}$ V.A. Nasonova Research Institute of Rheumatology, Rheumatology, Moscow, Russian Federation; ${ }^{2}$ I.M. Sechenov First Moscow State Medical University (Sechenov University), Pathomorphology, Moscow, Russian Federation

Background: Ultrasound (US) is a non-invasive and safe imaging method that allows in vivo differentiation of the morphological structures of subcutaneous fat (SCF) tissue in in normal and pathology.

Objectives: Reveal features of ultrasound changes in SCF in panniculitis (Pn). Methods: 57 patients $(f-45, m-12)$ aged $18-67$ years with an initial diagnosis of erythema nodosum and a disease duration of $3.6 \pm 1.4$ years were examined. In addition to the general clinical examination, a computed tomography of the chest organs and a pathomorphological examination of a skin biopsy from the site of the node were performed. Ultrasound was performed on a MyLabTwice apparatus (ESAOTE, Italy) using a multi-frequency linear transducer $(10-18 \mathrm{MHz})$ with the $\mathrm{PD}$ technique, the parameters of which were adapted for recording low-speed flows (PRF $300-600 \mathrm{~Hz}$, low filter, dynamic range - 20-40 dB), the presence of vascularization was assessed not only in the affected area, but also on the contralateral side using high-energy Doppler.

Results: 33 patients were diagnosed with septal Pn (SPn), 24 - lobular Pn (LPn). In all cases, the diagnosis was verified by histological examination. Ultrasound made it possible to assess the thickness, echoicity and vascularization of the SCF. In 35 patients, significant thickening of the SCF was revealed (as compared to the contralateral side), of which in 14 cases with SPn, in 21 - with LPn. Significant diffuse thickening of the SCF with the contralateral side was observed in 18 patients, incl. in $12(66 \%)$ patients with LPn. Limited thickening was more typical for SPn (73\%). A significant increase in the echoicity of the SCF was noted in all forms of $\mathrm{Pn}$. A "lobular" echo pattern with an anechogenic environment was observed in 25 patients, of which $18(72 \%)$ had LPn. An increase in vascularization compared to the contralateral side was recorded in 30 cases (SPn-17, LPn-13).

Conclusion: The obtained preliminary results indicate the important role of ultrasound in assessing the depth and prevalence of the inflammatory process at Pn. To clarify the diagnostic value of this method, further studies are needed on a larger sample of patients.

Disclosure of Interests: None declared

DOI: 10.1136/annrheumdis-2021-eular.663

\section{POS1389 IDIOPATHIC, RHEUMATOID ARTHRITIS AND DIABETES MELLITUS ASSOCIATED CARPAL TUNNEL SYNDROME: EVALUATION OF THE DEPTH OF THE CARPAL TUNNEL BY ULTRASONOGRAPHY}

A. Elsaman ${ }^{1}$, Y. Alzahrani ${ }^{2}$, H. Alzahrani ${ }^{2}$, A. Radwan ${ }^{1} .{ }^{1}$ Sohag University Hospital, Rheumatology and Rehabilitation, Sohag, Egypt; ${ }^{2}$ Armed Forces Specialized Center for Health Rehabilitation, Altaif, Kingdom of Saudi Arabia, Rehabilitation Depatment, Taif, Saudi Arabia

Background: The depth of the carpal tunnel is a relatively new sonographic parameter for evaluation of carpal tunnel syndrome (CTS). It showed a sensitivity and specificity comparable to cross-sectional area measurement. So far it is not clear how the depth can changes with different types of CTS [1, 2].

Objectives: is to assess the depth in 3 different types of CTS including idiopathic, rheumatoid arthritis, and diabetes mellitus associated CTS and to compare it with other sonographic and electro-physiologic scales.

Methods: We included a total number of 360 participants; including 289 with CTS (60 idiopathic, 106 diabetes associated, and 123 rheumatoid arthritis associated CTS), all fulfilled the criteria for electro-physiologic diagnosis according to the American Association of Electro Diagnostic Medicine; along with 71 nonCTS cases ( 20 healthy controls, 20 RA and 31 diabetic patients). Median nerve cross-sectional area (CSA); flattening ratio (FR); and depth of the carpal tunnel (DCT) were measured for all participants.

Results: We found the mean age $35.6 \pm 9.48$ years. The female-to-male ratio was 47:13. The sensitivities for CSA, FR and DCT were $74.7 \%, 68.9 \%$, and $75.1 \%$; respectively, and the specificities were $91.6 \%, 63.4 \%$ and $87.3 \%$; respectively. DCT was the best sonographic parameter with rheumatoid arthritis associated CTS (giving an accuracy of $88.6 \%$ ) and CSA was the best in the other two types (giving an accuracy of $87.5 \%$ for idiopathic CTS and $83.4 \%$ for diabetes associated CTS). Table 1 summarizes the sensitivity statistics among each of the three groups and all over the study participants.

Conclusion: The depth of the CTS showed the best accuracy in rheumatoid arthritis associated CTS followed by idiopathic CTS and finally diabetes mellitus associated CTS.

\section{REFERENCES}

[1] Elsaman AM, Thabit MN, Radwan AR, Ohrndorf S. Idiopathic Carpal Tunnel Syndrome: Evaluation of the Depth of the Carpal Tunnel by Ultrasonography. Ultrasound in medicine \& biology 2015; 41: 2827-35.

[2] AM E, Hamed A, Borai A, Radwan A. Carpal tunnel syndrome in rheumatoid arthritis patients: evaluation of the depth by ultrasonography.
[3] Elsaman AM, Thabit MN, Radwan AR, Ohrndorf S. Idiopathic Carpal Tunnel Syndrome: Evaluation of the Depth of the Carpal Tunnel by Ultrasonography. Ultrasound in medicine \& biology 2015; 41: 2827-35

Table 1. Sensitivity statistics for different US measures for CTS

\begin{tabular}{|c|c|c|c|c|c|}
\hline & & Idiopathic & RA & Diabetic & All \\
\hline \multicolumn{2}{|c|}{$\begin{array}{l}\text { Number of the CTS } \\
\text { cases }\end{array}$} & 60 & 123 & 106 & 289 \\
\hline \multicolumn{2}{|c|}{$\begin{array}{l}\text { Number of the } \\
\text { controls }\end{array}$} & 20 & 20 & 31 & 71 \\
\hline \multirow[t]{3}{*}{ CSA } & Sensitivity & $80 \%$ & $70.7 \%$ & $76.4 \%$ & $74.7 \%$ \\
\hline & Specificity & $95 \%$ & $90 \%$ & $90.3 \%$ & $91.6 \%$ \\
\hline & Accuracy & $87.5 \%$ & $80.4 \%$ & $83.4 \%$ & $83.1 \%$ \\
\hline \multirow[t]{3}{*}{ FR } & Sensitivity & $75 \%$ & $61.8 \%$ & $73.6 \%$ & $68.9 \%$ \\
\hline & Specificity & $60 \%$ & $65 \%$ & $64.5 \%$ & $63.4 \%$ \\
\hline & Accuracy & $67.5 \%$ & $63.4 \%$ & $69.1 \%$ & $66.1 \%$ \\
\hline \multirow[t]{3}{*}{ DCT } & Sensitivity & $75 \%$ & $82.1 \%$ & $67 \%$ & $75.1 \%$ \\
\hline & Specificity & $85 \%$ & $95 \%$ & $83.9 \%$ & $87.3 \%$ \\
\hline & Accuracy & $80 \%$ & $88.6 \%$ & $75.4 \%$ & $81.2 \%$ \\
\hline
\end{tabular}

CSA: cross sectional area, FR: flattening ratio, DCT: Depth of the carpal tunnel

Disclosure of Interests: None declared

DOI: 10.1136/annrheumdis-2021-eular.717

\section{\begin{tabular}{|l|l}
\hline POS1390 COMPARISON OF CAROTID SUBCLINICAL \\
\hline
\end{tabular} ATHEROSCLEROSIS AND STRUCTURAL DAMAGE IN AXIAL SPONDYLITIS WITH AND WITHOUT CONCOMITANT ANTERIOR UVEITIS. A MULTICENTER STUDY WITH 886 PATIENTS}

I. González-Mazón ${ }^{1}$, J. Rueda-Gotor ${ }^{1}$, I. Ferraz-Amaro² ${ }^{\text {, L. Sanchez-Bilbao }}$, F. Genre ${ }^{3}$, V. Calvo-Río ${ }^{1}$, S. Remuzgo-Martínez ${ }^{3}$, V. Pulito-Cueto ${ }^{3}$, A. Corrales ${ }^{1}$ L. Lera-Gómez ${ }^{3}$, V. Portilla ${ }^{1}$, V. Hernández-Hernández ${ }^{4}$, J. C. QuevedoAbeledo $^{5}$, C. Rodríguez-Lozano ${ }^{5}$, C. López-Medina ${ }^{6}$, M. L. Ladehesa Pineda ${ }^{6}$, S. Castañeda ${ }^{7}$, E. F. Vicente-Rabaneda ${ }^{7}$, C. Fernández-Carballido ${ }^{8}, M$. P. Martínez-Vidal ${ }^{8}$, D. Castro-Corredor ${ }^{9}$, J. Anino-Fernández ${ }^{9}$, D. Peiteado ${ }^{10}$, M. L. García Vivar ${ }^{11}$, E. Galindez ${ }^{11}$, E. Montes Pérez ${ }^{12}$, R. Demetrio-Pablo ${ }^{13}$, C. Fernández-Díaz', R. Blanco ${ }^{1}$, M. A. González-Gay ${ }^{1,3}$. 'Universitary Hospital Marques de Valdecilla, Rheumatology, Santander, Spain; ${ }^{2}$ Hospital Universitario de Canarias, Rheumatology, Santander, Spain; ${ }^{3}$ IDIVAL, Epidemiology, Genetics and Atherosclerosis Research Group on Systemic Inflammatory Diseases, Santander, Spain; ${ }^{4}$ Hospital Universitario de Canarias, , Rheumatology, Tenerife, Spain; ${ }^{5}$ Hospital Universitario de Gran Canaria Dr. Negrín, Rheumatology, Las Palmas, Spain; ${ }^{6}$ Reina Sofia Hospital, Rheumatology, Cordoba, Spain; ${ }^{7}$ Hospital de La Princesa, Rheumatology, Madrid, Spain; ${ }^{8}$ Hospital Universitario San Juan de Alicante, Rheumatology, Alicante, Spain; ${ }^{9}$ Hospital General Universitario de Ciudad Real, Rheumatology, Ciudad Real, Spain; ${ }^{10}$ Hospital Universitario La Paz-IdiPaz, Rheumatology, Madrid, Spain; ${ }^{11}$ Hospital Universitario Basurto, Rheumatology, Bilbao, Spain; ${ }^{12}$ Diagnóstico Médico Cantabria, DMC, Santander, Spain;

${ }^{13}$ Universitary Hospital Marques de Valdecilla, Ophtalmology, Santander, Spain

Background: Anterior uveitis $(\mathrm{AU})$ is one of the most frequent extra articular manifestations of axial spondyloarthritis (axSpA), present in around $25 \%$ of patients As with axSpA, AU has also been associated with the development of accelerated atherosclerosis ${ }^{1}$. If the presence of $\mathrm{AU}$ confers an increased cardiovascular (CV) risk or specific disease-related features to patients with axSpA remains unclear. Objectives: To compare the atherosclerotic burden, CV events, CV risk factors and disease related factors including structural damage in axSpA patients with and without $A U$. Methods: Cross-sectional analysis of the AtheSpAin cohort, a Spanish multicenter cohort designed for the study of atherosclerosis in axSpA, comparing axSpA patients with and without concomitant uveitis. Background information on CV and disease-related factors was reviewed. Data on CV risk and disease status at the time of the study were also obtained, including the structural damage assessed by the presence of syndesmophytes, the severity of the sacroiliitis (defined as grade 3 or 4 according to New York criteria), and the modified Stoke Ankylosing Spondylitis Spinal Score (mSASSS). Carotid ultrasound (US) was performed in all patients at the time of the study, including measurement of carotid intima-media wall thickness (cIMT) and plaque detection according to the Mannhein consensus criteria.

Results: A set of 886 axSpA patients were included. 709 (80.0\%) of them had no history of concomitant $A U$, which was present in the remaining $177(20.0 \%)$ The group with $\mathrm{AU}$ was older ( $50 \pm 11$ vs $48 \pm 13$ years, $p=0.05)$, had a higher proportion of patients with AS $(90.1 \%$ vs $76.3 \%, p=0.00)$ (Table 1$)$ and a longer disease duration $13(7-23)$ vs $7(2-16)$ years, $p=0.00]$. The prevalence of HLA-B27 was higher in AU patients ( $82 \%$ vs $67 \%$ ).

Remarkably, structural damage showed interesting differences between both groups (Table 1). AU patients had a higher prevalence of severe sacroiliits $(69 \%$ vs $49 \%, p=0.00$ ), which remained significant after adjustment for age, disease duration and $\mathrm{AS} / \mathrm{nr}$-axSpA ratio. Furthermore, a non-significant trend towards a 
higher prevalence of syndesmophytes (44\% vs $36 \%, \mathrm{p}=0.06)$ and hip involvement $(20 \%$ vs $15 \%, p=0.09)$ was observed in the group of $A U$.

Regarding CV risk features, no differences were observed in the prevalence of CV risk factors and events (Table 1). Patients with AU showed a higher cIMT in the crude analysis ( $665 \pm 156 \mathrm{~mm}$ vs $640 \pm 142 \mathrm{~mm}, \mathrm{p}=0.047)$, but no significant differences were observed after adjustment by age and sex $(\mathrm{p}=0.6)$. Prevalence of carotid plaques was comparable in both groups $(32 \%$ Vs $32 \%, p=0.84)$.

Table 1.

\begin{tabular}{|c|c|c|c|c|}
\hline \multirow[b]{2}{*}{ Men/Women, $\mathrm{n}$} & \multicolumn{2}{|c|}{$\begin{array}{l}\text { axSpA without axSpA with } \\
\text { uveitis }(n=709) \text { uveitis }(n=177)\end{array}$} & p & \multirow[t]{2}{*}{$\begin{array}{l}\mathrm{P} \text { (adjusted } \\
\text { model) }\end{array}$} \\
\hline & $477 / 232$ & $122 / 55$ & 0.68 & \\
\hline $\begin{array}{l}\text { Mean age (years) } \pm S D \text { at the time of } \\
\text { study }\end{array}$ & $48 \pm 13$ & $50 \pm 11$ & 0.049 & \\
\hline AS/nr-AxSpa & $541 / 168$ & $160 / 17$ & 0.000 & \\
\hline \multicolumn{5}{|l|}{ History of $\mathrm{CV}$ risk factors, $\mathrm{n}(\%)$} \\
\hline $\begin{array}{l}\text { Current smoker } \\
\text { Obesitty }\end{array}$ & $247(35)$ & $50(28)$ & 0.096 & \\
\hline Dyslipemia & $233(33)$ & $63(36)$ & 0.48 & \\
\hline Hypertension & $188(27)$ & $50(28)$ & 0.63 & \\
\hline Diabetes Mellitus & $50(7)$ & $14(8)$ & 0.69 & \\
\hline Chronic Kidney Disease & $18(3)$ & $4(2)$ & 0.99 & \\
\hline History of cardiovascular events, $\mathrm{n}(\%$ & $29(4)$ & $12(7)$ & 0.13 & \\
\hline \multicolumn{5}{|c|}{ Structural damage at the time of study } \\
\hline Presence of syndesmophytes, n (\%) & $253(36)$ & $77(44)$ & 0.063 & \\
\hline mSASSS & $5(1-15)$ & $6(0-16)$ & 0.31 & \\
\hline Severe sacroiliitis (grade 3,4$), \mathrm{n}(\%)$ & $348(49)$ & $122(69)$ & 0.000 & $0.000^{*}$ \\
\hline \multicolumn{5}{|l|}{ Carotid US data at the time of study } \\
\hline Carotid plaques, n (\%) & 225 (32) & $57(32)$ & 0.84 & \\
\hline IMT (mm) & $640 \pm 142$ & $665 \pm 156$ & 0.047 & $70.6^{\star *}$ \\
\hline IMT > $=0.900 \mathrm{~mm}$ & $36(5)$ & $10(6)$ & 0.72 & \\
\hline
\end{tabular}

*: adjusted by age, disease duration and AS/nr-axSpA ratio

**: adjusted by age and sex

Abbreviations: $\mathrm{AS}=$ ankylosing spondylitis. $\mathrm{AxSpA}=$ axial spondylitis. $\mathrm{CV}=$ cardiovascular. IMT

$=$ intima-media wall thickness. $\mathrm{Nr}$-axSpA $=$ no-radiographic axial spondylitis

Conclusion: The presence of $\mathrm{AU}$ does not confer additional $\mathrm{CV}$ risk to axSpA patients, although it is associated with a more severe structural damage in our series. REFERENCES:

[1] Conkar S, Güven Yılmaz S, Koska İÖ, Berdeli A, Mir S. Evaluation of development of subclinical atherosclerosis in children with uveitis. Clin Rheumatol. 2018 May;37(5):1305-1308.

Disclosure of Interests: None declared

DOI: 10.1136/annrheumdis-2021-eular.909

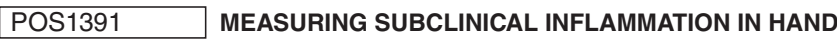 AND FOREFOOT IN PATIENTS WITH ARTHRALGIA USING 1.5T OR 3.0T MRI: DOES FIELD STRENGTH MATTER?}

D. Krijbolder ${ }^{1}$, M. Verstappen ${ }^{1}$, F. Wouters ${ }^{1}$, L. R. Lard ${ }^{2}$, P. D. De Buck ${ }^{3}$, J. Verisvan Dieren ${ }^{4}$, M. Reijnierse ${ }^{5}, \mathrm{H}$. Bloem ${ }^{5}, \mathrm{~A}$. Van der Helm - van Mil ${ }^{1,6}$. ${ }^{1}$ Leiden University Medical Center, Department of Rheumatology, Leiden, Netherlands; ${ }^{2}$ LangeLand Ziekenhuis, Department of Rheumatology, Zoetermeer, Netherlands; ${ }^{3}$ Haaglanden Medical Center, Department of Rheumatology, Den Haag, Netherlands; ${ }^{4}$ Reumazorg Zuid West Nederland, Department of Rheumatology, Goes, Netherlands; ${ }^{5}$ Leiden University Medical Center, Department of Radiology, Leiden, Netherlands; ${ }^{6}$ Erasmus Medical Center, Department of Rheumatology, Rotterdam, Netherlands

Background: Magnetic resonance imaging (MRI) of small joints sensitively detects inflammation. MRI-detected subclinical inflammation, and tenosynovitis in particular, has been shown predictive for RA development in patients with arthralgia. These scientific data are mostly acquired on 1.0T-1.5T MRI scanners. However, 3.0T $\mathrm{MRI}$ is nowadays increasingly used in practice. Evidence on the comparability of these field strengths is scarce and it has never been studied in arthralgia where subclinical inflammation is subtle. Moreover, comparisons never included tenosynovitis, which is, of all imaging features, the strongest predictor for progression to RA. Objectives: To determine if there is a difference between 1.5T and 3.0T MRI in detecting subclinical inflammation in arthralgia patients.

Methods: 2968 locations (joints, bones or tendon sheaths) in hands and forefeet of 28 arthralgia patients were imaged on both 1.5T and 3.0T MRI. Two independent readers scored for erosions, osteitis, synovitis (according to RAMRIS) and tenosynovitis (as described by Haavaardsholm et al.). Scores were also summed as total inflammation (osteitis, synovitis and tenosynovitis) and total RAMRIS (erosions, osteitis, synovitis and tenosynovitis) scores. Interreader reliability (comparing both readers) and field strength agreement (comparing 1.5T and 3.0T) was assessed with interclass correlation coefficients (ICCs). Next, field strength agreement was assessed after dichotomization into presence or absence of inflammation. Analyses were performed on patient- and location-level.
Results: ICCs between readers were excellent (>0.90). Comparing 1.5 and 3.0T revealed excellent ICCs of 0.90 (95\% confidence interval 0.78-0.95) for the total inflammation score and $0.90(0.78-0.95)$ for the total RAMRIS score. ICCs for individual inflammation features were: tenosynovitis: $0.87(0.74-0.94)$, synovitis $0.65(0.24-0.84)$ and osteitis $0.96(0.91-0.98)$. The field strength agreement on dichotomized scores was $83 \%$ for the total inflammation score and $89 \%$ for the total RAMRIS score. Of the individual features, agreement for tenosynovitis was the highest (89\%). Analyses on location- level showed similar results.

Conclusion: Agreement of subclinical inflammation scores on 1.5T and 3.0T were good to excellent, in particular for tenosynovitis. This suggests that scientific evidence on predictive power of MRI in arthralgia patients, obtained on 1.5T, can be generalized to 3.0T when this field strength would be used for diagnostic purposes in daily practice. Disclosure of Interests: None declared DOI: 10.1136/annrheumdis-2021-eular.1417

\section{POS1392 \\ ECHOCARDIOGRAPHIC FINDINGS IN PSORIATIC ARTHRITIS, RHEUMATOID ARTHRITIS AND CONTROLS}

A. B. Rodriguez-Romero ${ }^{1}$, J. R. Azpiri-López ${ }^{2}$, I. J. Colunga-Pedraza ${ }^{1}$, D. Á. Galarza-Delgado ${ }^{1}$, N. Guajardo-Jauregui ${ }^{1}$, S. Lugo-Perez ${ }^{2}$, A. Cárdenas ${ }^{1}$, H. Azpiri-Diaz ${ }^{2}$, O. A. Cepeda-Ayala ${ }^{2} .{ }^{1}$ Hospital Universitario "Dr. José Eleuterio González", Universidad Autónoma de Nuevo León, Rheumatology Service, Monterrey, Mexico; ${ }^{2}$ Hospital Universitario "Dr. José Eleuterio González", Universidad Autónoma de Nuevo León, Cardiology Service, Monterrey, Mexico

Background: Psoriatic arthritis (PsA) is a chronic inflammatory arthropathy associated with cardiovascular abnormalities (1). The echocardiography is a non-invasive tool useful in the detection of cardiac abnormalities, which may be the only manifestation of cardiac involvement preceding a global dysfunction. However, echocardiographic differences between PsA patients, rheumatoid arthritis (RA) patients, and controls have not yet been well described.

Objectives: To analyze the echocardiographic parameters in PsA patients and to compare them with RA patients and controls.

Methods: This cross-sectional, observational and comparative study, included thirty-six patients (nineteen in each group), aged 40-75 years, with PsA and RA who fulfilled the CASPAR (Classification criteria for Psoriatic Arthritis) and ACR/EULAR 2010 classification criteria, respectively, matched by age, gender and comorbidities with nineteen healthy controls. Exclusion criteria were a poor echocardiographic window, patients with a previous atherosclerotic cardiovascular disease (ischemic heart disease, cerebrovascular accident or peripheral arterial disease), and pregnancy. Transthoracic echocardiogram was performed and reviewed by 2 board-certified cardiologists, in all study subjects. Comparisons were done with X2, Kruskall Wallis or ANOVA.

Results: There were not differences in the demographic characteristics between groups (Table 1). When comparing echocardiographic findings a statistically significant difference was found in the prevalence of diastolic dysfunction, being more prevalent in PsA and RA patients compared with controls (52.6\% vs $52.6 \%$ vs $5.3 \%$, $\mathrm{p}=0.002)$, likewise the presence of mild mitral valve regurgitation was higher $(84.2 \%$ vs $53.6 \%$ vs $10.5 \%, p=0.001)$ and mild pulmonary valve regurgitation $(68.4 \%$ vs $10.5 \%$ vs $0 \%, p=0.001$ ). Prevalence of abnormal left ventricular geometry was higher in PsA and RA patients than controls ( $68.4 \%$ vs $63.2 \%$ vs $21.1 \%, p=0.006)$

Table 1. Comparison of demographic characteristics and echocardiographic findings between patients with PsA, RA and controls.

\begin{tabular}{|c|c|c|c|c|}
\hline & $\begin{array}{l}\text { PsA } \\
(n=19)\end{array}$ & $\begin{array}{l}\text { RA } \\
(n=19)\end{array}$ & $\begin{array}{l}\text { Controls } \\
(n=19)\end{array}$ & $p$ \\
\hline Age, years $\pm S D$ & $54.7 \pm 7.7$ & $55.4 \pm 9.9$ & $55.3 \pm 5.9$ & NS \\
\hline Female, $\mathrm{n}(\%)$ & $11(57.9)$ & $11(57.9)$ & $11(57.9)$ & NS \\
\hline Diabetes Mellitus & $4(21.1)$ & $3(15.8)$ & $2(10.5)$ & NS \\
\hline Hypertension & $10(52.6)$ & $8(42.1)$ & $7(36.8)$ & NS \\
\hline Dyslipidemia & $10(52.6)$ & $4(21.1)$ & $7(36.8)$ & NS \\
\hline Active smoking & $4(21.1)$ & $2(10.5)$ & $5(26.3)$ & NS \\
\hline Disease duration, years (p25-p75) & $6(4-14)$ & $7(5-18)$ & - & NS \\
\hline $\begin{array}{l}\text { DAS28-CRP, mean } \pm \text { SD } \\
\text { Echocardiographic findigs }\end{array}$ & $2.2 \pm 0.8$ & $3.1 \pm .8$ & - & 0.003 \\
\hline Diastolic dysfunction, n (\%) & $10(52.6)$ & $10(52.6)$ & $1(5.3)$ & 0.002 \\
\hline LV mass index, $\mathrm{g} / \mathrm{m}^{2}(\mathrm{p} 25-\mathrm{p} 75)$ & $78.9(55.9-86.9)$ & $73.7(61.0-85.7)$ & $69.5(52.0-98.7)$ & NS \\
\hline LVEF, \pm mean SD & $62.3 \pm 6.1$ & $59.7 \pm 8.6$ & $62.9 \pm 6.1$ & NS \\
\hline TAPSE, $\mathrm{cm} \pm \mathrm{SD}$ & $21.8 \pm 2.7$ & $22.4 \pm 2.7$ & $23.7 \pm 3.1$ & NS \\
\hline Mild aortic regurgitation, $\mathrm{n}(\%)$ & $5(26.3)$ & $4(21.1)$ & $1(5.3)$ & NS \\
\hline Mild mitral regurgitation, $\mathrm{n}(\%)$ & $16(84.2)$ & $10(52.6)$ & $2(10.5)$ & $<0.001$ \\
\hline Mild pulmonary regurgitation, $\mathrm{n}(\%)$ & $13(68.4)$ & $2(10.5)$ & $0(0)$ & $<0.001$ \\
\hline Mild tricuspid regurgitation, $\mathrm{n}(\%)$ & 15 (83.3) & $13(76.5)$ & $11(57.9)$ & NS \\
\hline LV geometry alterations, n (\%) & $13(68.4)$ & $12(63.2)$ & $4(21.1)$ & 0.006 \\
\hline Concentric remodeling, $\mathrm{n}(\%)$ & $12(63.2)$ & $10(52.6)$ & $4(21.1)$ & 0.025 \\
\hline
\end{tabular}

NS, non-significant; DAS28-CRP, disease activity score using 28 joints and $C$ reactive protein; $L V$, left ventricular; LVEF, left ventricular ejection fraction; TAPSE, tricuspid annular plane systolic excursion 